\title{
Elevation of total serum immunoglobulin $E$ is associated with asthma in nonallergic individuals
}

\author{
K.M. Beeh*, M. Ksoll ${ }^{\#}$, R. Buhl*
}

Elevation of total serum immunoglobulin $E$ is associated with asthma in nonallergic individuals. K.M. Beeh, M. Ksoll, R. Buhl. C)ERS Journals Ltd 2000.

ABSTRACT: Elevated serum immunoglobulin (Ig)E is the hallmark of atopy, and contributes to asthma and bronchial hyperresponsiveness in atopic individuals. In contrast, the significance of $\mathrm{IgE}$ in nonallergic subjects is less clear. The aim of the present study is to clarify a potential association of IgE and asthma in absence of clinical allergy.

To this purpose 1,219 consecutive patients of a pulmonary practice were evaluated. Nonallergic patients were defined by negative skin prick test, history of atopy and specific IgE, 509 subjects $(42 \%)$ were nonallergic. Among these, 80 patients $(16 \%)$ had elevated total IgE levels $\left(>150 \mathrm{U} \cdot \mathrm{mL}^{-1}\right)$. Prevalence and severity of asthma in nonallergic subjects with $\operatorname{IgE}>150 \mathrm{U} \cdot \mathrm{mL}^{-1}$ were compared with subjects with normal IgE levels, and lung function parameters were correlated with serum IgE in all nonallergic subjects and asthmatics.

Asthma was more prevalent in nonallergic subjects with elevated IgE levels than in nonallergic subjects with normal IgE $(39 \%$ versus $14 \%$; $<<0.001)$. Lung function values of nonallergic asthmatics were lower for forced expiratory volume in one second (FEV1) \% predicted $(66+20 \%$ versus $83 \pm 17 \%$; $<<0.001)$, FEV1\% forced vital capacity (FVC) $(70 \pm 14 \%$ versus $81 \pm 8 \% ; p<0.001)$ and forced mid expiratory flow (FEF25-75) (1.7 $\pm 0.9 \mathrm{~L} \cdot \mathrm{s}^{-1}$ versus $\left.2.8 \pm 0.9 \mathrm{~L} \cdot \mathrm{s}^{-1} ; \mathrm{p}=0.002\right)$ in patients with high IgE compared to asthmatics with normal IgE, and were negatively correlated with $\log \operatorname{IgE}$ levels in all nonallergic asthmatics. (FEV1 \% pred: $\mathrm{r}=-0.5, \mathrm{p}<0.001$; FEV1 \% FVC: $r=-0.53, p<0.001 ;$ FEF25-75: $r=-0.52, p<0.001)$. In the whole study population, multivariate analysis showed a greater than fivefold asthma risk for nonallergic individuals with serum IgE $>150 \mathrm{U} \cdot \mathrm{mL}^{-1}$.

These data support the role of IgE as risk factor for asthma independent of allergy, and they further challenge the definition of intrinsic asthma as "non-IgE mediated" entity.

Eur Respir J 2000; 16: 609-614.

Bronchial asthma is characterized by lower respiratory tract inflammation leading to bronchial hyperresponsiveness (BHR) and variable, reversible airflow obstruction. A still widely used classification [1] distinguishes allergic, immediate type hypersensitivity mediated ("extrinsic") from nonallergic ("intrinsic") asthma. However, several lines of evidence challenge the dualistic concept of extrinsic and intrinsic asthma [2]. Inflammatory cytokines [3] and high affinity IgE receptor expression in bronchial biopsies [4] were similar in allergic and intrinsic asthmatics. BURRows [5] showed that every form of asthma was somehow associated with IgE, and a paper by SUNYER et al. [6] revealed an independent association of asthma and serum IgE levels. However, these findings have not been unquestioned, in particular since asthma diagnosis was solely based on "self-reported asthma" in questionnaires [5], and the number of allergens tested to verify or rule out atopy was very small $[5,6]$, thus possibly leading to underdiagnosis of allergic disease.

Since the original description of IgE by IsHIZAKA et al. [7] in 1966, the knowledge about the role of $\operatorname{IgE}$ in the
*Pulmonary Dept, University Hospital, Mainz, Germany, and "Pulmonary Practice, Frankfurt, Germany.

Correspondence: K.M. Beeh Pulmonary Dept Internal Medicine University Hospital Langenbeckstr. 1 55131 Mainz

Germany

Fax: 496131175510

\section{Keywords: Asthma} immunoglobulin E lung function nonallergics

Received: November 191999

Accepted after revision June 12000 pathogenesis of allergic diseases has profoundly increased. Serum levels of allergen specific and total $\mathrm{IgE}$ are strongly associated with the clinical grade of sensitization and disease severity in allergic patients [8]. IgE has also been shown to be a major contributing factor for the development of bronchial hyperresponsiveness in asthmatics [9], and ongoing research focuses on the possibility and clinical feasibility of blocking IgE-mediated disorders by monoclonal anti-IgE-antibodies $[10,11]$.

Determination of total serum IgE levels is used as a screening tool for atopy, although the sensitivity and specificity of serum IgE determination still remains controversial $[12,13]$. With normal values differing in their range, an upper limit of $120-180 \mathrm{U} \cdot \mathrm{mL}^{-1}$ for serum-IgE levels is generally accepted to provide a feasible tool to distinguish atopics from nonatopics [14]. Besides atopy, elevated $\operatorname{IgE}$ levels are occasionally observed in disorders like parasitic infection [15], myeloma [16], chronic inflammatory bowel diseases [17], human immunodeficiency virus (HIV) infection [18] or rare disorders like Job's syndrome [19]. In addition, smoking [20, 21] and 
exposure to diesel exhaust or benzole [22] have been shown to result in enhanced IgE production. Nevertheless, significant elevation of serum IgE is occasionally also observed in clearly nonallergic individuals, either with asthma or not, and little is known about the clinical significance of such findings.

With this background the aim of the present study was to analyse the relationship between asthma and total and specific serum $\operatorname{IgE}$ in a large sample of patients in order to further elucidate a possible contributory role of serum $\operatorname{IgE}$ to the pathogenesis of bronchial asthma in nonallergic individuals.

\section{Methods}

\section{Patients}

Files from 1,219 consecutive patients newly admitted to a pulmonary specialist practice with respiratory symptoms or for a health check-up between January 1995 and January 1996 were retrospectively investigated. The practice is settled in the inner city of Frankfurt, Germany. Patients are either referred from general practitioners, but may also present on their own responsibility, with a clear predominance of self-admitted patients. The data were made anonymous by one and consecutively analysed by another investigator.

All patients underwent thorough clinical evaluation (age, race, sex, occupation, patient and family history, smoking status, physical examination), skin prick test (SPT) with allergen extracts, lung function tests (bodyplethysmography and spirometry), and nonspecific bronchial provocation (histamine) to verify bronchial hyperresponsiveness, if baseline lung function revealed no abnormalities (FEV1 $\geq 85 \%$ pred). A blood sample was drawn to determine total and specific serum IgE levels.

A diagnosis of asthma was based on the following criteria: 1) airflow obstruction (FEV1 <85\%) with reversibility $>12 \%$ and at least $200 \mathrm{~mL}$ from baseline after bronchodilation [23]; or 2) positive histamine challenge combined with typical clinical signs like dry cough and wheezing in absence of acute respiratory tract infection [24]. Serum IgE levels did not influence the possible diagnosis of asthma. Allergy was defined as at least one positive SPT result against common allergens, detectable levels of specific IgE against at least one out of ten allergens Enzyme-linked Allergic Sorbent Test/Radio Allergo Sorbent Test (EAST/PAST class $\geq 1$ ), or patient history of atopic dermatitis or allergic rhinoconjunctivitis. Consequently, nonallergics were defined by complete absence of the above mentioned criteria.

Based on these criteria all nonallergics were selected for analysis. Nonallergic subjects were further divided into a) patients with elevated serum IgE levels $\left(>150 \mathrm{U} \cdot \mathrm{mL}^{-1}\right)$ and b) nonallergic patients with normal IgE levels. Patients with history or clinical signs of parasitic infection, chronic inflammatory bowel disease, myeloma, and HIV-infection were excluded.

\section{Skin prick test}

Skin prick tests (Bencard, Neuss, Germany) included the following allergens: grass pollen mix, rye grass; weed pollen mix, tree pollen mix, dog, cat, feather mix, horse; guinea pig, Dermatophagoides pteronyssinus, Dermatophagoides farinae, Alternaria, Aspergillus fumigatus, and Penicilium notatum. Results were read as reactions grading from $0-4$ according to wheal and erythema diameters in $\mathrm{mm}$, as previously described [25]. In patients with negative standard SPT but elevated total IgE $>150 \mathrm{U} \cdot \mathrm{mL}^{-1}$, an additional SPT with food allergens was performed to exclude food sensitizations including egg, cows' milk, tomato, caseine, crab, meat mix, flour mix and spice mix. Only patients with complete negative SPT were regarded as nonallergic.

\section{Pulmonary function tests}

Pulmonary function tests were performed in a wholebody plethysmograph (Masterlab II, Jaeger, Wuerzburg, Germany). The best of three consecutive spirometry recordings were used. Measurements included forced vital capacity (FVC), FEV1, FEF25-75 and airway resistance (Raw). Histamine challenge was performed using a modified reservoire method (PARI Provocation Test II, Dr. Beckmann Co., Germany) [26]. Briefly, histamine chloride $0.2 \%$ was administered by an inhalation reservoire in increasing volumes $(1.25,2.5,5$ and $10 \mathrm{~L})$, resulting in applied histamine doses of $25 \mu \mathrm{g}, 50 \mu \mathrm{g}, 100 \mu \mathrm{g}$ and 200 $\mu \mathrm{g}$, respectively. The test was regarded positive, if a $20 \%$ fall of baseline FEV1 occurred (PD20). A dose of $>200 \mu \mathrm{g}$ histamine defined a negative response. Airflow reversibility tests, if necessary, were performed after application of $200 \mu \mathrm{g}$ of aerosolized salbutamol (2 puffs), followed by a second lung function test after $15 \mathrm{~min}$. Reference values were obtained from the European Community for Steel and Coal [27].

\section{Total and specific immunoglobulin E measurements}

Total and specific IgE measurements were performed using an IgE MicroTurbo-Assay (Fooke Labs., Neuss, Germany). For total IgE levels, seven World Health Organization (WHO) standards were used $(0,2,5,20,100$, $\left.500,1500 \mathrm{U} \cdot \mathrm{mL}^{-1}\right)$, whereas for specific IgE levels, four standards (EAST/PAST classes 1-4) were used. All patients were tested for total and specific IgE (grass, weed, birch, der far, der pt, asp fum, alt aft, clad herb, cat, dog). A result of EAST class $\geq 1$ was considered positive. Normal values for total $\mathrm{IgE}$ given by the manufacturer ranged between $20-120 \mathrm{U} \cdot \mathrm{mL}^{-1}$ for adults in this assay. A cut-off point of $150 \mathrm{U} \cdot \mathrm{mL}^{-1}$ was used to determine total serum $\mathrm{IgE}$ elevation (mean $\pm 2 \mathrm{SD}$ ). Similar to the general population, $\mathrm{IgE}$ values were $\log$ normally distributed in the patients, hence $\log \operatorname{IgE}$ was used for statistical analysis.

\section{Statistical analysis}

Statistical analysis was performed using the intercooled STATA 5.0 software package (State Corp., Texas, USA). Unless specified otherwise, data are reported as mean \pm SD. Shapiro-Wilk Test was used to test values for normal distribution. Group comparison tests were performed using the two-sided t-test for normally, and Mann-Whitney 
U-test for non-normally distributed values. Categorical variables between groups were compared using Fisherexact test. Correlational coefficients were calculated by simple linear regression after log transformation of serum IgE values. Odd ratios and relative risks were calculated by multivariate logistic regression model adjusted for confounding parameters. For all statistical analyses, a value of $\mathrm{p}<0.05$ was considered statistically significant.

\section{Results}

\section{Patients}

Five-hundred and nine nonallergic individuals (42\%) were identified in a population of 1,219 consecutive patients newly admitted to a pulmonary specialist practice over one year. Among all nonallergic patients, 80 individuals $(16 \%)$ had elevated serum IgE levels $>150 \mathrm{U} \cdot \mathrm{mL}^{-1}$ (range: 150-1109 U.mL $\mathrm{mL}^{-1}$ ), whereas the remaining 429 patients had normal levels $\left(<150 \mathrm{U} \cdot \mathrm{mL}^{-1}\right)$. A total number of 93 patients were diagnosed as having asthma. There were no differences regarding age, sex distribution, ethnics, and occupational exposure to inhalants with potential effects on respiratory function (e.g. inorganic and organic dusts, solvents, air conditioning) between all nonallergic individuals and asthmatics, whether they had normal or elevated serum IgE levels. In particular, smoking habits and number of consumed cigarettes per day were similar in all groups. There was no correlation of serum IgE levels with current smoking status (i.e. number of cigarettes per day; $r=0.09 ; \mathrm{p}=0.27)$ or age $(\mathrm{r}=-0.004 ; \mathrm{p}=0.92)$ in all nonallergic patients. For nonallergic asthmatics, the percentage of patients already using inhaled corticosteroids was higher in the group of subjects with elevated $\operatorname{IgE}$ levels $(68 \%$ versus $47 \% ; \mathrm{p}=0.04$ ) (table 1 ).

\section{Diagnoses}

Acute upper respiratory tract infection (URTI) was the leading primary diagnosis in all nonallergic patients $(30 \%)$, followed by chronic obstructive pulmonary disease (COPD, 23\%) and asthma (19.4\%); 19\% of the patients were found to have no disorder (health check-up or nonspecific, unclassifiable symptoms). Interestingly, the frequency of an asthma diagnosis was higher in nonallergies with elevated $\operatorname{IgE}$ than in nonallergics with normal $\operatorname{IgE}$ $(39 \%$ versus $14 \% ; \mathrm{p}<0.001)$. Nasal sinus disease was present in $9 \%$ of all nonallergics, with higher prevalence in

Table 1. - Characteristics of nonallergic asthmatics

\begin{tabular}{|c|c|c|}
\hline & $\operatorname{IgE}<150 \mathrm{U} \cdot \mathrm{mL}^{-1}$ & $\operatorname{IgE}>150 \mathrm{U} \cdot \mathrm{mL}^{-1}$ \\
\hline Subjects $n$ & 62 & 31 \\
\hline Age yrs & $39 \pm 13$ & $42 \pm 16$ \\
\hline Sex M/F & $38 / 62$ & $45 / 55$ \\
\hline Caucasian race & 96 & 94 \\
\hline $\begin{array}{l}\text { Occupational exposure } \\
\text { to inhalants }\end{array}$ & 13 & 6 \\
\hline Current smokers & 18 & 19 \\
\hline Cigarettes $\cdot$ day $^{-1}$ & $15 \pm 5$ & $11 \pm 12$ \\
\hline Pet ownership & 18 & 23 \\
\hline ICS usage & 47 & $68^{*}$ \\
\hline
\end{tabular}

Data presented as percentage unless otherwise stated. IgE: immunoglobulin E; ICS: inhaled corticosteroids; *: $p=0.04$. patients with $\mathrm{IgE}<150 \mathrm{U} \cdot \mathrm{mL}^{-1}$ than in patients with IgE $>150 \mathrm{U} \cdot \mathrm{mL}^{-\mathrm{P}}(10 \%$ versus $4 \%)$, but without statistical significance $(\mathrm{p}=0.07)$. Regarding other diagnoses, there were no differences between these two groups ( $p>0.05$, all comparisons).

\section{Lung function}

Lung function parameters indicating obstructive airway disease were lowest in nonallergic patients with elevated serum $\operatorname{IgE}>150 \mathrm{U} \cdot \mathrm{mL}^{-1}$. Absolute and relative values of spirometry were significantly lower in these patients when compared with nonallergic patients with normal IgE levels (table 2). Accordingly, airway resistance (Raw) was highest in nonallergics with IgE-elevation.

In the subgroup of nonallergic asthmatics, lung function parameters were lower in those patients with high $\operatorname{IgE}>150$ $\mathrm{U} \cdot \mathrm{mL}^{-1}$ than in nonallergic asthmatics with normal IgE values, too. Reversibility measured as the percentage of change in FEV1 from baseline after beta-agonist use tended to be better in nonallergics asthmatics with high IgE, but this was not statistically significant (table 3 ).

Lung function parameters indicating obstructive airway disease were weakly, but highly significantly, correlated with $\log$ IgE levels in all nonallergic individuals (log Raw: $\mathrm{r}=0.4, \mathrm{p}<0.001$; FEV1 (\% pred): $\mathrm{r}=-0.28, \mathrm{p}<0.001$; FEV1\%FVC: $\mathrm{r}=-0.38, \mathrm{p}<0.001$; FEF25-75: $\mathrm{r}=-0.28, \mathrm{p}=$ $0.001)$. This association was even stronger, when only the subset of asthmatic nonallergic subjects were analysed (fig. 1).

There were no differences in the median PD20 between nonallergic asthmatics with normal or elevated IgE (100 $\mu \mathrm{g}$ histamine, both groups). However, this observation was clearly biased by the fact, that asthmatics with high IgE had worse lung function, and therefore, less frequently underwent histamine challenge $(8 / 31$ versus $26 / 62, \mathrm{p}=0.05)$ to verify bronchial hyperresponsiveness.

\section{Multivariate analysis}

A multivariate logistic regression analysis was performed to further assess and quantify risk factors for an asthma diagnosis in nonallergic patients. Serum IgE elevation $>150 \mathrm{U} \cdot \mathrm{mL}^{-1}$ (OR: 5.1; 95\% CI: 2.6-10.1) and age $<40$ yrs (OR: $3.8 ; 95 \%$ CI: $2-7.5$ ) were associated with an enhanced risk of present asthma, whereas sex, smoking status, occupational exposure to inhalants, pet ownership and history of nasal sinus disease were not (table 4).

Table 2. - Lung function parameters in all nonallergic patients

\begin{tabular}{lcc}
\hline & $\operatorname{IgE}<150 \mathrm{U} \cdot \mathrm{mL}^{-1}$ & $\operatorname{IgE}>150 \mathrm{U} \cdot \mathrm{mL}^{-1}$ \\
\hline Subjects n & 429 & 80 \\
FEV1 L & $2.83 \pm 0.9$ & $2.56 \pm 0.9^{*}$ \\
FEV1 \% & $88 \pm 20$ & $81 \pm 25^{\oplus}$ \\
FEV1/\%FVC \% & $81 \pm 12$ & $75 \pm 13^{\#}$ \\
FEF25-75 L.s ${ }^{-1}$ & $2.8 \pm 1.4$ & $2.3 \pm 1.3^{\dagger}$ \\
log Raw $\mathrm{cmH}{ }_{2} \mathrm{O} \cdot \mathrm{s} \cdot \mathrm{L}^{-1}$ & $1.15 \pm 0.5$ & $1.45 \pm 0.5^{\#}$ \\
\hline
\end{tabular}

Data presented as mean \pm SD. IgE: immunoglobulin E; FEV1: forced expiratory volume in one second; FVC: forced vital capacity; FEF $25-75 \%$ : forced mid-expiratory flow; Raw: airway resistance; *: $p=0.02 ;{ }^{\uparrow}: \mathrm{p}=0.007{ }^{\dagger}: \mathrm{p}=0.005 ;{ }^{*}: \mathrm{p}<0.001$. 
Table 3. - Lung function parameters in nonallergic asthmatics

\begin{tabular}{lcc}
\hline & IgE & IgE \\
& $<150 \mathrm{U} \cdot \mathrm{mL}^{-1}$ & $>150 \mathrm{U} \cdot \mathrm{mL}^{-1}$ \\
\hline Subjects n & 62 & 1 \\
FEV1 L & $2.8 \pm 0.8$ & $2.1 \pm 0.8^{*}$ \\
FEV1 \% & $83 \pm 17$ & $66 \pm 20^{*}$ \\
FEV1/\%FVC \% & $81 \pm 8$ & $70 \pm 14^{*}$ \\
FEF25-75 L.s s $^{-1}$ & $2.8 \pm 0.9$ & $1.7 \pm 0.9^{*}$ \\
log Raw $\mathrm{cmH} \mathrm{H}_{2} \mathrm{O} \cdot \mathrm{s} \cdot \mathrm{L}^{-1}$ & $1.38 \pm 0.48$ & $1.75 \pm 0.5^{\#}$ \\
$\begin{array}{l}\text { Reversibility }(\Delta \mathrm{FEV} \% \\
\text { change from baseline) }\end{array}$ & $19.7 \pm 5.2$ & $21 \pm 5.1$ \\
\hline
\end{tabular}

Data presented as mean $\pm \mathrm{SD}$. IgE: immunoglobulin E; FEV1: forced expiratory volume in one second; FVC: forced vital capacity; FEF25-75\%: forced mid-expiratory flow; Raw: airway resistance; *: $\mathrm{p}<0.001 ;{ }^{\uparrow}: \mathrm{p}=0.007{ }^{*}: \mathrm{p}<0.002$.

\section{Discussion}

The possible association of serum IgE levels and asthma, independent of specific allergic sensitization, has been previously reported [5, 6]. However, these studies have some important limitations. It is thus questionable, whether the patients described in these reports really represented nonallergic subjects or were underdiagnosed allergic patients. To avoid these problems, in this study the diagnosis of allergy and asthma was based on extensive history, clinical features, a broad range of allergy tests, lung function parameters, $\beta$-agonist reversibility of airway obstruction, and bronchial challenge with histamine.

Apart from the retrospective character of this analysis, the present study may be limited by a selectional bias, since the patients included in this study are not a representative sample from the general population, but patients presenting to a pulmonary specialist. However, despite a possible referral bias, a large sample of nonallergic subjects using clear-cut definitions of asthma and allergy were analysed, as described by the diagnostic procedures above. The results of this study clearly suggest that elevation of serum $\operatorname{IgE}$ is observed not only in allergic asthmatics, but may also be encountered in clearly nonallergic individuals, and

a)

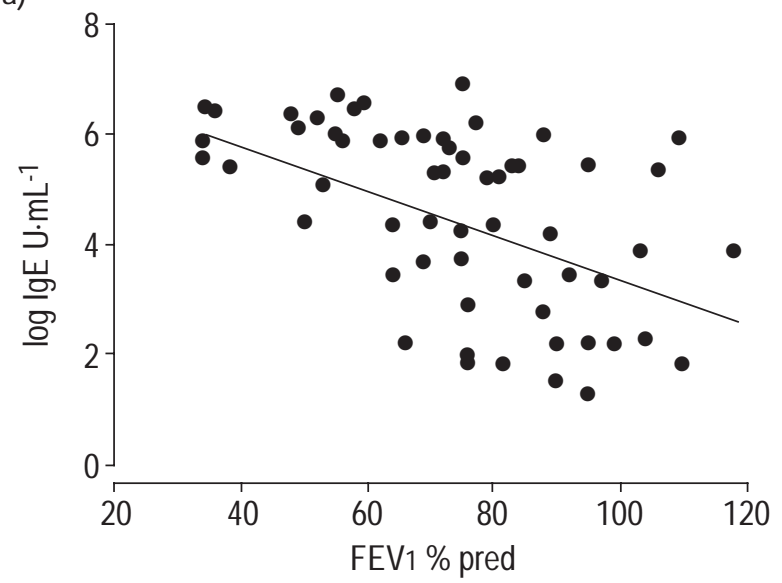

that serum $\operatorname{IgE}$ may contribute to the pathogenesis and severity of asthma in these nonallergic patients.

This conclusion is based on several observations. Firstly, nonallergics with elevated $\operatorname{IgE}$ levels were more likely to have a diagnosis of asthma in comparison to nonallergies with normal IgE, resulting in a more than five-fold increased risk for asthma in nonallergic subjects with $\mathrm{IgE}$ $>150 \mathrm{U} \cdot \mathrm{mL}^{-1}$. Secondly, the extent of obstructive airway disease was closely correlated with IgE levels in nonallergic asthmatics as well. Thus, not only did the likelihood of an asthma diagnosis increase with increasing serum IgE levels, but the severity of asthma also increased with airflow obstruction at the time of presentation.

However, the possible mechanisms of the association of increased total serum $\operatorname{IgE}$ and asthma in nonallergic patients remain to be fully understood for the following reasons.

The IgE levels observed may represent specific $\operatorname{IgE}$ against unknown allergens not included in our test panel. From the authors' point of view, this explanation is most unlikely, since their patients were extensively tested, and especially patients with high total IgE underwent additional diagnostic procedures, including tests to rule out food allergy. Furthermore, none of these patients had a typical asthma history, suggesting allergen exposure as a cause. It is therefore unlikely that the whole study population represents individuals with monosensitizations towards rare allergens not tested.

Cigarette smoking has been reported to be associated with both elevated IgE levels and lung function impairment in adults $[28,29]$, thus providing a possible explanation for our findings. However, no differences in smoking habits and number of cigarettes smoked per day were observed between nonallergic asthmatics with high and normal IgE levels; and total IgE was not correlated with the extent of current smoking (i.e. number of cigarettes $\cdot$ day $^{-1}$ ).

As long as a follow-up of the study participants is not performed, it is difficult to assess whether nonallergics with high $\operatorname{IgE}$ levels were rather pre-allergic than nonallergic and may develop specific sensitizations in their later lives. At least in the patients, who still attend the

b)

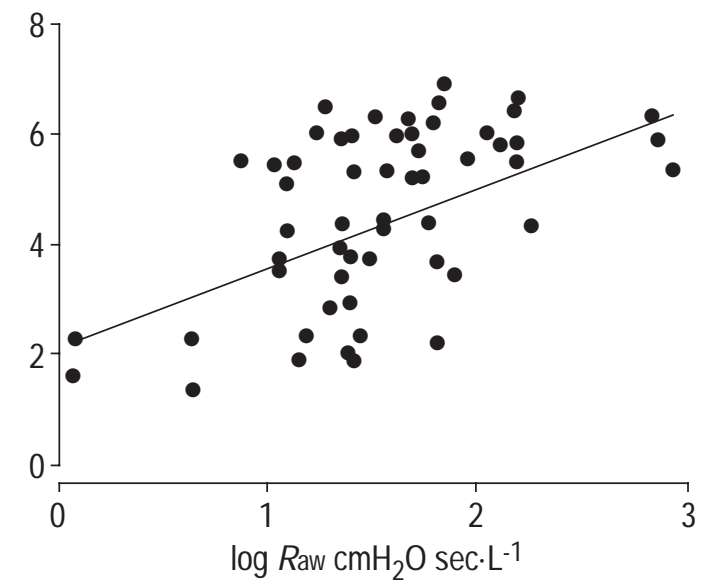

Fig. 1. - Correlation of a) Forced expiratory volume in one second (FEV1) and b) log Raw immunoglobulin E (IgE) levels in nonallergic asthmatics $(\mathrm{n}=93)$ : $\mathrm{p}<0.001$ for each and $\mathrm{r}=-0.5$ and 0.51 for $\mathrm{a})$ and $\mathrm{b}$ ) respectively. 
Table 4. - Multivariate odd ratios (OR) for asthma in nonallergic patients

\begin{tabular}{llc}
\hline Variable & OR & $95 \%$ CI \\
\hline IgE $>150 \mathrm{U} \cdot \mathrm{mL}^{-1}$ & $5.1^{*}$ & $2.6-10.1$ \\
Age $<40$ yrs & $3.8^{*}$ & $2-7.5$ \\
Current smoking & 0.65 & $0.31-1.4$ \\
Sinus disease & 1.4 & $0.4-4.8$ \\
Pet ownership & 1.9 & $0.8-4.2$ \\
Male sex & 0.67 & $0.34-1.3$ \\
\hline
\end{tabular}

IgE: immunoglobulin E; 95\% CI: 95\% confidence interval; *: $\mathrm{p}<0.001$.

practice frequently, this was not the case, yet a systematical analysis remains to be completed.

Total IgE elevation could be a nonspecific reaction secondary to asthmatic inflammation, which might stimulate B-cell production of polyclonal IgE [30]. This interpretation could provide a possible explanation for the correlation of asthma severity and total IgE levels seen in the study population, in which total IgE may represent an surrogate marker of asthmatic inflammation. Both lung function and serum IgE are affected by anti-inflammatory therapy. Although information about asthma medication is incomplete, at least the percentage of subjects initially using inhaled corticosteroids was higher in those asthmatics with elevated IgE. A potential bias of antiinflammatory therapy would therefore rather strengthen the findings presented.

An attractive explanation is supported by genetic linkage analyses, which have revealed a possible co-inheritance of the genetic loci representing bronchial hyperresponsiveness and atopy, i.e. a "high IgE"-phenotype [31, 32]. In that case, the presented observations would represent a noncausal, merely associated phenomenon.

Finally, it is tempting to speculate whether $\operatorname{IgE}$ is an independent sensitizer of effector cells (mast cells and basophils) triggering bronchial hyperresponsiveness even in the absence of specific sensitizations in nonallergic patients [9]. This concept is supported by several in vitro studies, which have shown that bronchial hyperresponsiveness in tracheal segments may occur after incubation with sera of patients with high IgE levels [33]. In this setting, it might be feasible to use monoclonal anti-IgE as asthma therapy even in nonallergic asthmatics.

In summary, this study supports the evidence that serum $\operatorname{IgE}$ is associated with bronchial hyperresponsiveness and asthma independently of atopy status and specific allergic sensitizations, although this association may be limited to a selected patient population. It is thus questionable, whether a distinction of "extrinsic" and "intrinsic" asthma should be based on the presence or absence of an elevated serum concentration of IgE [34]. Further studies are clearly warranted to elucidate whether these observations represent a causal, pathogenic, or noncausal association.

\section{References}

1. Rackemann FM. A working classification of asthma. Am J Med 1947; 3: 601-606.

2. Kroegel C, Jaeger L, Walker C. Is there a place for intrinsic asthma as a distinct immunopathological entity? Eur Respir J 1997; 10: 513-515.

3. Humbert M, Durham SR, Ying S, et al. IL-4 and IL-5 mRNA and protein in bronchial biopsies from patients with atopic and nonatopic asthma: evidence against "intrinsic" asthma being a distinct immunopathologic entity. Am J Respir Crit Care Med 1996; 154: 1497-1504.

4. Humbert M, Grant JA, Taborda-Barata L, et al. Highaffinity IgE Receptor-Bearing cells in bronchial biopsies from atopic and nonatopic asthma. Am J Respir Crit Care Med 1996; 153: 1931-1937.

5. Burrows B, Martinez FD, Halonen M, Barbee RA, Cline MG. Association of asthma with serum IgE levels and skin-test reactivity to allergens. $N$ Engl J Med 1989; 320: 271-277.

6. Sunyer J, Anto JM, Soriano JB, Roca J. Total serum IgE is associated with asthma independently of specific IgE levels. Eur Respir J 1996; 9: 1880-1884.

7. Ishizaka K, Ishizaka T, Hornbrook MM. Physicochemical properties of reaginic antibody. IV Presence of a unique immunoglobulin as a carrier of reaginic activity. J Immunol 1966; 97: 75-85.

8. Brown WG, Halonen MJ, Kaltenborn WT, Barbee RA. The relationship of respiratory allergy, skin test reactivity, and serum $\operatorname{IgE}$ in a community population sample. $J$ Allergy Clin Immunol 1979; 63: 328-335.

9. Rabe KF. Mechanisms of immune sensitization of human bronchus. Am J Respir Crit Care Med 1998; 158: 161170.

10. Fahy JV, Fleming HE, Wong HH, et al. The effect of an anti-IgE monoclonal antibody on the early and late-phase responses to allergen inhalation in asthmatic subjects. $\mathrm{Am}$ $J$ Respir Crit Care Med 1997; 155: 1828-1834.

11. Casale TB, Bernstein IL, Busse WW, et al. Use of an antiIge humanized monoclonal antobody in ragweed-induced allergic rhinits. J Allergy Clin Immunol 1997; 100: 110121.

12. Klink M, Cline MG, Halonen M, Burrows B. Problems in defining normal limits for serum IgE. J Allergy Clin Immunol 1990; 85: 440-444.

13. Laurent J, Noirot C, Ansquer JC, Laurent G, Kestenbaum $\mathrm{S}$, Lagrue G. How to define the normal level of serum IgE in adults? Ann Med Interne Paris 1995; 136: 419-422.

14. Haupt I, Jung HJ, Nuske M, Ringelmann R. Studies on normal range of serum IgE concentration. Immun Infetrt 1979; 7: 97-102.

15. Sutton BJ, Gould HJ. The human IgE network. Nature 1993; 366: 421-428.

16. Amlot PL, Green LA. Atopy and immunoglobuline E concentrations in Hodgkin's disease and other lymphomas. BMJ 1978; 11: 327-329.

17. Levo Y, Shalit M, Wollner S, Fich A. Serum IgE levels in patients with inflammatory bowel disease. Ann Allergy 1986; 56: 85-87.

18. Grieco MH. Immunoglobulins and hypersensitivity in human immunodeficiency virus (HIV) infection. J Allergy Clin Immunol 1989; 84: 11.

19. Moneret-Vautrin DA, Kanny G, Thinus G. Hyperglobulinemia E syndrome with recurrent infections (Job's syndrome). Rev Med Interne 1999; 20: 133-140.

20. Barbee RA, Halonen M, Kaltenborn W, Lebowitz M, Burrows B. A longitudinal study of serum IgE in a community cohort: correlations with age, sex, smoking, and atopic status. J Allergy Clin Immunol 1987; 79: 919-927.

21. Gerrard JW, Heiner DC, Ko CG, Mink J, Meyers A, Dosman JA. Immunoglobulin levels in smokers and nonsmokers. Ann Allergy 1980; 44: 261-262. 
22. Takatuji S, Suzuki S, Muranaka M, Miyamoto T. Influence of environmental factors on IgE production. Ciba Found Symp 1989; 147: 188-201.

23. American Thoracic Society. Lung function testing: selection of reference values and interpretative strategies. Am Rev Respir Dis 1991; 144: 1202-1218.

24. American Thoracic Society. Standards for the diagnosis and care of patients with chronic obstructive pulmonary disease (COPD) and asthma. Am Rev Respir Dis 1987; 136: 225-243.

25. Terr AI. Skin Prick Testing. In: Stites DP, Terr AI, eds. Basic and Clinical Immunology. Connecticut, Appleton and Lange, 1991; p. 375-377.

26. Working Group "Bronchial Provocation Tests" of the German Society of Pneumology. Guidelines for the application of bronchial provocation tests with pharmacological stimuli. Pneumologie 1998; 52: 215-220.

27. Quanjer PH, Tammeling GJ, Cotes JE, Pedersen OF, Peslin R, Yernault J. Lung volumes and forced ventilatory flows. Report Working Party Standardization of Lung Function Tests, European Community for Steel and Coal. Official Statement of the European Respiratory Society. Eur Respir J 1993; 6: Suppl. 16, 5-40.

28. Dow L, Coggon D, Campbell MJ, Osmond C, Holgate
ST. The interaction between immunoglobulin $\mathrm{E}$ and smoking in airflow obstruction in the elderly. Am Rev Respir Dis 1992; 146: 402-407.

29. Reed CE. The natural history of asthma in adults: the problem of irreversibility. J Allergy Clin Immunol 1999; 103: 539-547.

30. Burrows B, Martinez FD, Cline MG, Lebovitz MD. The relationship between parental and children's serum IgE and asthma. Am J Respir Crit Care Med 1995; 152: 14971500.

31. Postma DS, Bleecker ER, Amelung PJ, et al. Genetic susceptibility to asthma-bronchial hyperresponsiveness coinherited with a major gene for atopy. $N$ Engl J Med 1995; 333: 894-900.

32. van Herwerden L, Harrap SB, Wong ZYH, et al. Linkage of high-affinity $\operatorname{IgE}$ receptor gene with bronchial hyperreactivity, even in absence of atopy. Lancet 1995; 346: 1262-1265.

33. Watson N, Bodtke K, Coleman RA, et al. Role of IgE in hyperresponsiveness induced by passive sensitization of human airways. Am J Respir Crit Care Med 1997; 155: 839-844.

34. Ostergaard PA. Non-IgE-mediated asthma in children. Acta Paediatr Scand 1985; 74: 713-719. 